Research Article

\title{
Karyotype differentiation in three species of Tripogandra Raf. (Commelinaceae) with different ploidy levels
}

\author{
André Marques, Fernando Roa and Marcelo Guerra \\ Laboratório de Citogenética Vegetal, Departamento de Botânica, Universidade Federal de Pernambuco, \\ Recife, PE, Brazil.
}

\begin{abstract}
Most species of the genus Tripogandra (Commelinaceae) are taxonomically poorly circumscribed, in spite of having a relatively stable basic number $x=8$. Aiming to estimate the cytological variation among Tripogandra species carrying this base number, several structural karyotypic characters were investigated in the diploid T. glandulosa, the hexaploid $T$. serrulata, and the octoploid $T$. diuretica. A careful evaluation of chromosome size and morphology did not reveal clear chromosome homeologies among karyotypes. The mean chromosome size was strongly reduced in the octoploid species, but not in the hexaploid species. They also differed largely in the $\mathrm{CMA}^{+}$banding pattern and in the number of $5 \mathrm{~S}$ and $45 \mathrm{~S}$ rDNA sites per monoploid chromosome complement. All three species showed proximal $\mathrm{DAPI}^{+}$heterochromatin, although in $T$. serrulata this kind of heterochromatin was only visible after FISH. Further, the meiosis in $T$. serrulata was highly irregular, suggesting that this species has a hybrid origin. The data indicate that, in spite of the conservation of the base number, these species are karyologically quite different from each other.
\end{abstract}

Key words: Tripogandra, cytotaxonomy, rDNA sites, CMA/DAPI bands, meiosis.

Received: December 4, 2009; Accepted: April 4, 2010.

The genus Tripogandra Raf. (Commelinaceae, tribe Tradescantieae, subtribe Tradescantiinae) comprises approximately 22 species, some of which are restricted to Mexico, while others are distributed throughout Mexico, Central America, and South America (Handlos, 1975). These species are characterized principally by the presence of dimorphic stamens and double cincinni (Handlos, 1975). Recently, molecular data have revealed that some Tripogandra species are grouped into one of the clades of the genus Callisia (Bergamo, 2003; Evans et al., 2003; Burns, 2006), suggesting that Tripogandra is a polyphyletic group. Cytotaxonomic analyses, mainly those that seek to identify the basic chromosome number, have contributed to the understanding of the phylogenetic relationships of many species groups (reviewed by Guerra, 2008), and can be useful in evaluating the relationships among species of this genus.

Within the family Commelinaceae, the subtribe Tradescantiinae, which includes Tripogandra, Callisia, Tradescantia, and Gibasis, stands out by its wide variation in basic numbers, chromosome morphology, and chromosome sizes (Jones and Kenton, 1984; Pitrez et al., 2001). The haploid number $n=8$ and its euploid multiples pre-

Send correspondence to Marcelo Guerra. Departamento de Botânica, Centro de Ciências Biológicas, Universidade Federal de Pernambuco, Rua Nelson Chaves s/n, 50670-420 Recife, PE, Brazil. E-mail: msfguerra@ hotmail.com. dominate in Tripogandra, with $x=8$ largely accepted as the basic number of the genus, while $n=5,6$, and 8 are encountered in Gibasis, $n=6,7$, and 8 in Callisia, and $n=6$ or multiples prevail in Tradescantia (Jones and Jopling, 1972). Although Tripogandra, Callisia, Gibasis, and Tradescantia share the basic number $x=8$, these genera show great diversity in chromosome morphology and ploidy levels, hindering an understanding of the cytotaxonomy of the subtribe (Handlos, 1970).

Cytogenetic analyses using other karyotype parameters, such as C-banding and staining with fluorochromes, have also contributed to an understanding of the relationships among some Commelinaceae species (Jones and Kenton, 1984; Kenton, 1991; Sakurai and Ichikawa, 2001). Parokonny et al. (1992) showed that some cryptic species of Gibasis can be clearly distinguished using techniques such as fluorescence in situ hybridization (FISH) and genomic in situ hybridization (GISH). However, this type of chromosome analysis is still restricted to just a few genera of the subtribe, and the cytology of a number of genera, such as Callisia and Tripogandra, has not been studied yet with any of these techniques.

In the present work several structural karyotype characteristics were analyzed in three species of Tripogandra (T. diuretica, $T$. glandulosa, and $T$. serrulata) with $x=8$, in order to understand the cytotaxonomical relationships among them. We also attempted to identify which structural characteristic of these karyotypes was best conserved 
and could represent a karyological synapomorphy of the genus. We investigated the structure of the interphase nuclei, the distribution of heterochromatin by fluorochrome staining with chromomycin $\mathrm{A}_{3}$ (CMA) and 4',6-diamidino-2-phenylindole (DAPI), and the number and location of the $5 \mathrm{~S}$ and $45 \mathrm{~S}$ rDNA sites by in situ hybridization (FISH). Previous chromosome counts had reported $2 n=16$ for T. glandulosa, $2 n=32,39,48$, ca. 50 for T. serrulata, and $2 n=62+1 \mathrm{~B}, 64$ for T. diuretica (Simmonds, 1954; Celarier, 1955; Lewis et al., 1967; Handlos, 1970; Jones and Jopling, 1972; Pitrez et al., 2001). The meiotic behavior of the two polyploid species was also analyzed in order to evaluate the stability of these species.

\section{Materials and Methods}

\section{Plant material}

Samples of Tripogandra diuretica, T. glandulosa, and $T$. serrulata were analyzed. All plant samples investigated grew in the experimental garden at the Department of Botany of the Federal University of Pernambuco, and the vouchers were deposited in the UFP herbarium of this university. Voucher numbers, provenances, and general cytological data for each sample are presented in Table 1.

\section{Slide preparation}

Root tips were pre-treated with 8-hydroxyquinoline $(0.002 \mathrm{M})$ for $5 \mathrm{~h}$ at $18^{\circ} \mathrm{C}$, fixed in absolute alcohol/glacial acetic acid $(3: 1, \mathrm{v} / \mathrm{v})$ for 2-24 $\mathrm{h}$ at room temperature, and stored at $-20{ }^{\circ} \mathrm{C}$. Subsequently, they were washed three times in distilled water and digested in a $2 \%(\mathrm{w} / \mathrm{v}$ $0.02 \mathrm{U} / \mathrm{mL}$ ) cellulase (Onozuka) and $20 \%(\mathrm{v} / \mathrm{v}-120 \mathrm{U} / \mathrm{mL})$ pectinase (Sigma) solution for $1-2 \mathrm{~h}$ at $37^{\circ} \mathrm{C}$. Meristems were squashed in a drop of $45 \%$ acetic acid and frozen in liquid nitrogen to remove the coverslip. The slides were stained with DAPI $(2 \mu \mathrm{g} / \mathrm{mL})$ :glycerol $(1: 1, \mathrm{v} / \mathrm{v})$ solution to permit selection of the best cells. Subsequently, the slides were destained in ethanol/glacial acetic acid $(3: 1, \mathrm{v} / \mathrm{v})$ for $30 \mathrm{~min}$ at room temperature and transferred to absolute ethanol overnight at $10^{\circ} \mathrm{C}$. Slides were air dried and aged for three days at room temperature for CMA/DAPI staining (Barros-e-Silva and Guerra, 2010).

For meiotic analysis, young inflorescences from $T$. diuretica and T. serrulata were fixed and stored as previously described. Prior to slide preparation, the material was washed twice in distilled water, anthers were squashed in a drop of $45 \%$ acetic acid, and the coverslip was removed after freezing in liquid nitrogen.

\section{CMA/DAPI staining}

For CMA/DAPI fluorochrome banding, aged slides were stained with $0.1 \mathrm{mg} / \mathrm{mL} \mathrm{CMA} \mathrm{(Sigma)} \mathrm{for} 1 \mathrm{~h}$ and counterstained with $1 \mu \mathrm{g} / \mathrm{mL}$ DAPI (Sigma) for $30 \mathrm{~min}$. The slides were mounted in 1:1 (v/v) McIlvaine's bufferglycerol with $2.5 \mathrm{mM} \mathrm{MgCl}_{2}$ (pH 7.0) and kept in the dark

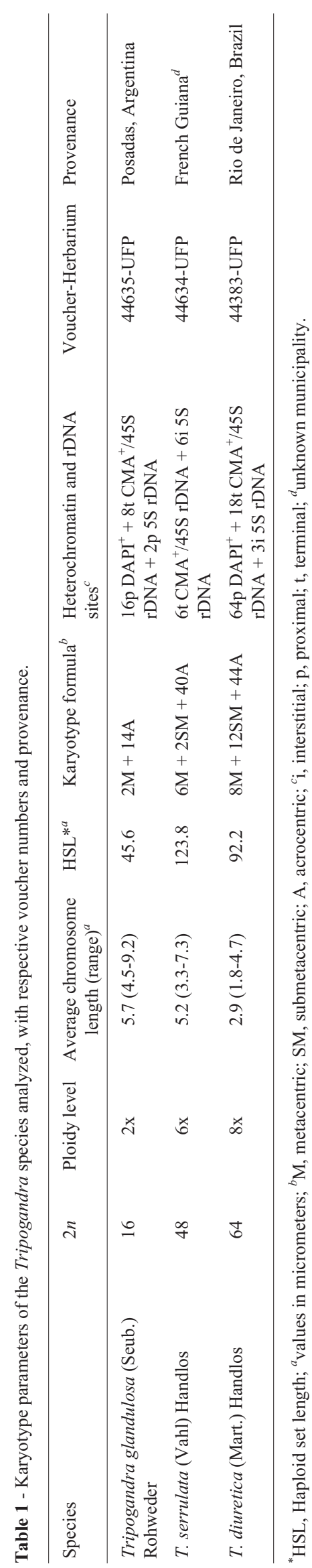


at room temperature for 3 days before analysis, as described by Barros-e-Silva and Guerra (2010). Well-spread cells were captured with a CCD Cohu camera on a Leica DMLB epifluorescence microscope using the Leica Q-FISH software. The slides were destained again and stored at $-20^{\circ} \mathrm{C}$.

\section{Fluorescence in situ hybridization (FISH)}

FISH procedure was based on Pedrosa et al. (2002) with minor modifications. Briefly, slides were treated with RNase at $37{ }^{\circ} \mathrm{C}$ for $1 \mathrm{~h}$, washed three times, in $2 \mathrm{x}$ SSC for 5 min each, and digested with pepsin at $37^{\circ} \mathrm{C}$ for $20 \mathrm{~min}$. The preparations were post-fixed in $1 \%$ (para)formaldehyde in 1x PBS for $10 \mathrm{~min}$ and dehydrated in an ethanol series.

Two rDNA probes, D2 and R2, were used to locate the $5 \mathrm{~S}$ and $45 \mathrm{~S}$ rDNA sites, respectively. D2 is a 500-bp fragment of the 5S rDNA repeat unit from Lotus japonicus (Pedrosa et al., 2002) and R2 is a 6.5-kb fragment that contains a 45S rDNA repeat unit from Arabidopsis thaliana (Wanzenböck et al., 1997). The D2 probe was labeled with Cy3-dUTP (Invitrogen) and the R2 probe was labeled with digoxigenin-11-dUTP (Life Technologies) by nick translation. The hybridization mixture contained $50 \%$ formamide (v/v), 10\% dextran sulfate (w/v), 2x SSC, and $2-5 \mathrm{ng} / \mu \mathrm{L}$ of probe. The probe mixture was denatured at $75{ }^{\circ} \mathrm{C}$ for $10 \mathrm{~min}$ and the chromosome denaturation was undertaken at $75^{\circ} \mathrm{C}$ for $6 \mathrm{~min}$. After overnight hybridization at $37^{\circ} \mathrm{C}$, slides were washed in the following order: $2 \mathrm{x} \mathrm{SSC}$ at room temperature, $2 \mathrm{x} \mathrm{SSC}, 0.1 \times \mathrm{SSC}$, and $2 \mathrm{x} \mathrm{SSC}$ at $42{ }^{\circ} \mathrm{C}$, and $2 \mathrm{x} \mathrm{SSC}$ at room temperature, for $5 \mathrm{~min}$ each. The digoxigenin probe was detected with sheep anti-digoxigenin FITC conjugate (Dako) and amplified with rabbit antisheep FITC conjugate (Roche). All slides were mounted in DAPI $(4 \mu \mathrm{g} / \mathrm{mL})$ that was diluted 1:1 (v/v) in Vectashield (Vector). Metaphase images were acquired as indicated above and were later edited in Adobe Photoshop CS3.

\section{Chromosome measurements and idiograms}

The total chromosome length (S) and the chromosomes arm ratios ( $\mathrm{AR}=$ long/short arm) were estimated using the Adobe Photoshop CS3 software. An idiogram summarizing most karyotype data for each species was constructed based on chromosome measurements of four well-spread cells, disregarding the length of the secondary constriction. The chromosomes were ordered by size from the largest to the smallest.

\section{Results}

Chromosome numbers, chromosome morphology, and nuclear structure

The karyotype parameters of the Tripogandra species analyzed are shown in Table 1 including average chromosome length.

According to the nomenclature that was proposed by Delay (1949) for interphase nuclei, T. glandulosa exhibited reticulate nuclei, with a dense and uniformly distributed chromatin structure, $T$. diuretica nuclei showed a semireticulate structure with irregularly distributed chromatin, and $T$. serrulata nuclei displayed an intermediary chromatin structure between these two types (Figures 1a-c). Condensation of the prophase chromosomes was uniform along the chromosomes of T. glandulosa (Figure 1d), while there were some regions that were less condensed than others in T. diuretica and T. serrulata (Figures 1e,f).

\section{CMA/DAPI staining and FISH}

The pericentromeric regions of all chromosomes of Tripogandra glandulosa $(2 n=16)$ were generally observed as weak DAPI ${ }^{+}$bands, which were better contrasted after FISH (Figure 1g). $\mathrm{CMA}^{+}$bands were observed on the short arms of the eight acrocentric chromosomes (Figure 2a), with a pair of them showing a much larger and brighter band. The distribution of the 45S rDNA sites coincided with the eight $\mathrm{CMA}^{+}$bands, while the 5S rDNA sites were localized in the interstitial/proximal regions of the long arms of two acrocentric chromosomes (Figure 2b).

The $\mathrm{CMA}^{+}$bands of $T$. serrulata $(2 n=48)$ were also co-localized with $45 \mathrm{~S}$ rDNA sites on the short arms of six acrocentric chromosomes, four of which were brighter than the other two (Figure 2c,d). DAPI ${ }^{+}$bands were not observed with direct CMA/DAPI staining (Figure 1h), although weak heterochromatic bands were sometimes observed after FISH in the interstitial and centromeric regions (not included in the idiograms) (Figure 2d). 5S rDNA sites were located in the interstitial region of three pairs of acrocentric chromosomes, one of them with very small signals (inserts in Figure 2d). Exceptionally, one of these sites was found co-localized with a $\mathrm{CMA}^{+}$band (see insert in Figure 2c).

Tripogandra diuretica $(2 n=64)$ had DAPI ${ }^{+}$bands in the pericentromeric region of all chromosomes (Figure 1i), and $\mathrm{CMA}^{+}$bands co-localized with $45 \mathrm{~S}$ rDNA sites on the short arms of 10 submetacentric and eight acrocentric chromosomes, three of them weakly stained (arrowheads in Figures $2 \mathrm{e}, \mathrm{f})$. In some cells, three chromosome pairs with $45 \mathrm{~S}$ rDNA sites appeared to have short arms slightly longer due to the decondensation of the nucleolar organizing regions. We observed 5S rDNA sites in the interstitial region of a pair of submetacentric chromosomes, and also in one small acrocentric chromosome (Figure 2f). The idiograms in Figure 3 summarize these data. Chromosome pairs homozygous or heterozygous for bands or rDNA sites were represented in the idiograms as a single chromosome having these marks.

\section{Meiotic analysis}

Meiosis in T. serrulata was irregular, with the formation of many univalents and only a few bivalent chromosomes in most diakinesis and metaphase I cells analyzed (Figures $4 \mathrm{a}, \mathrm{b}$ ). In the remaining cells the pairing configura- 
tion was not clear. Bridges and laggard chromosomes were observed in most cells in anaphase I and II, and one to seven micronuclei were found in telophase II (Figures $4 c, d$ ).
Tripogandra diuretica, on the other hand, showed regular meiosis with the formation of 32 bivalent chromosomes in metaphase I and micronuclei in only $3 \%$ of the tetrads.

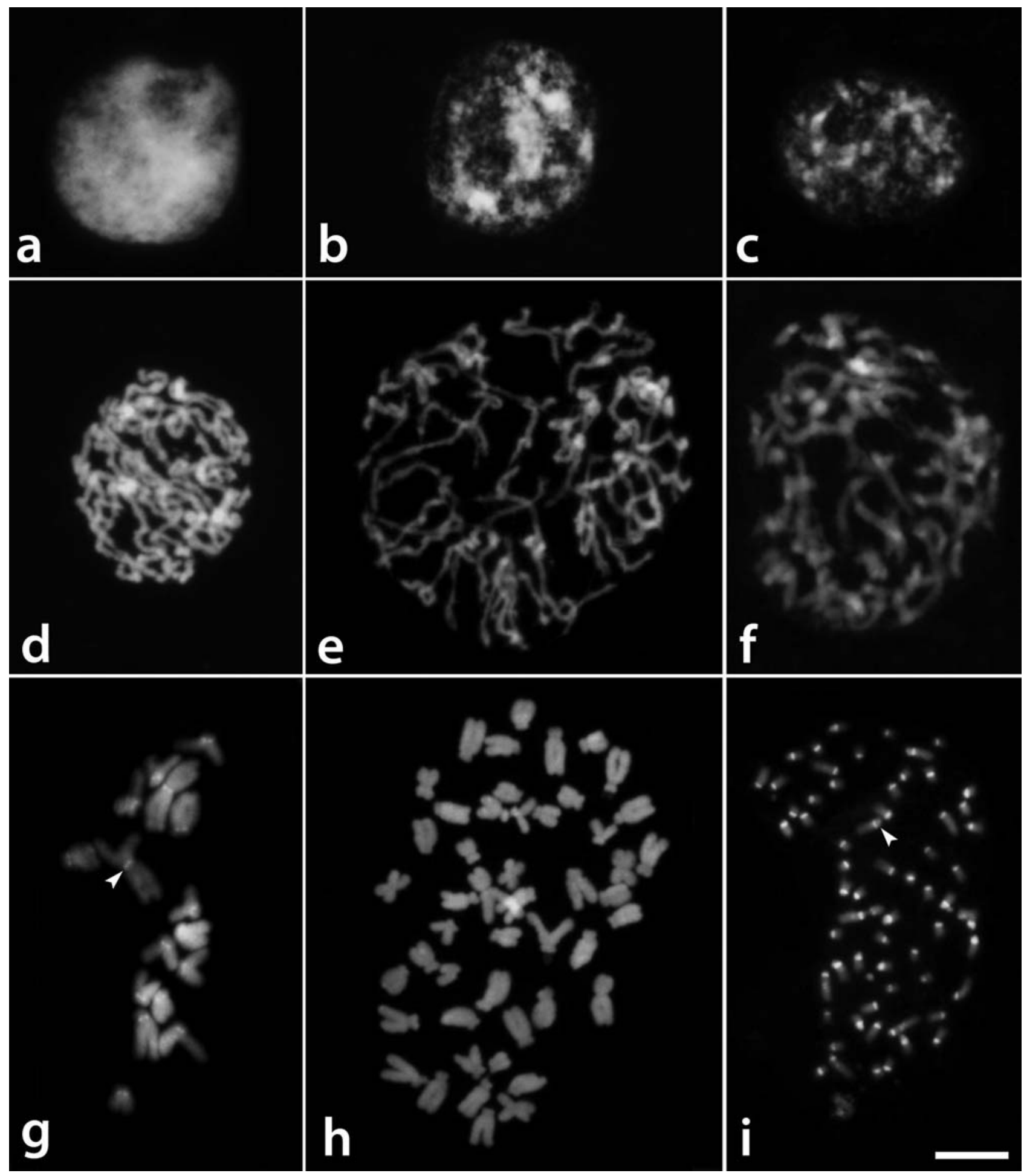

Figure 1 - DAPI stained cells of Tripogandra species showing the interphase nuclear structure (a-c), the prophase chromosome condensation patterns (d-f), and the metaphase chromosomes (g-i). a, d, g - T. glandulosa; b, e, h- T. serrulata; c, f, i - T. diuretica. Observe the variations in chromatin density and distribution in the interphase nuclei and in the chromosomes at prophase. Arrowheads point to centromeric bands in $\mathrm{g}$, i. Bar corresponds to $10 \mu \mathrm{m}$. 


\section{Discussion}

The three species of Tripogandra analyzed here had distinct karyotypes and different ploidy levels $(2 x, 6 x, 8 x)$. In addition to the chromosome number $2 n=48$ (hexaploid) that was commonly observed in $T$. serrulata (Celarier, 1955; Lewis et al., 1967; and the present work), Handlos
(1970) reported some tetraploid individuals with $2 n=32$. The chromosome numbers $2 n=39$ and $2 n=$ ca. 50 for $T$. serrulata reported by Lewis et al. (1967) and Simmonds (1954), respectively, are probably miscounts.

The karyotype formulae of the three species analyzed here [T. glandulosa, $2 n=16(2 \mathrm{M}+14 \mathrm{~A}) ; T$. serrulata, $2 n=48(6 \mathrm{M}+2 \mathrm{SM}+40 \mathrm{~A}) ;$. . diuretica, $2 n=64(8 \mathrm{M}+$

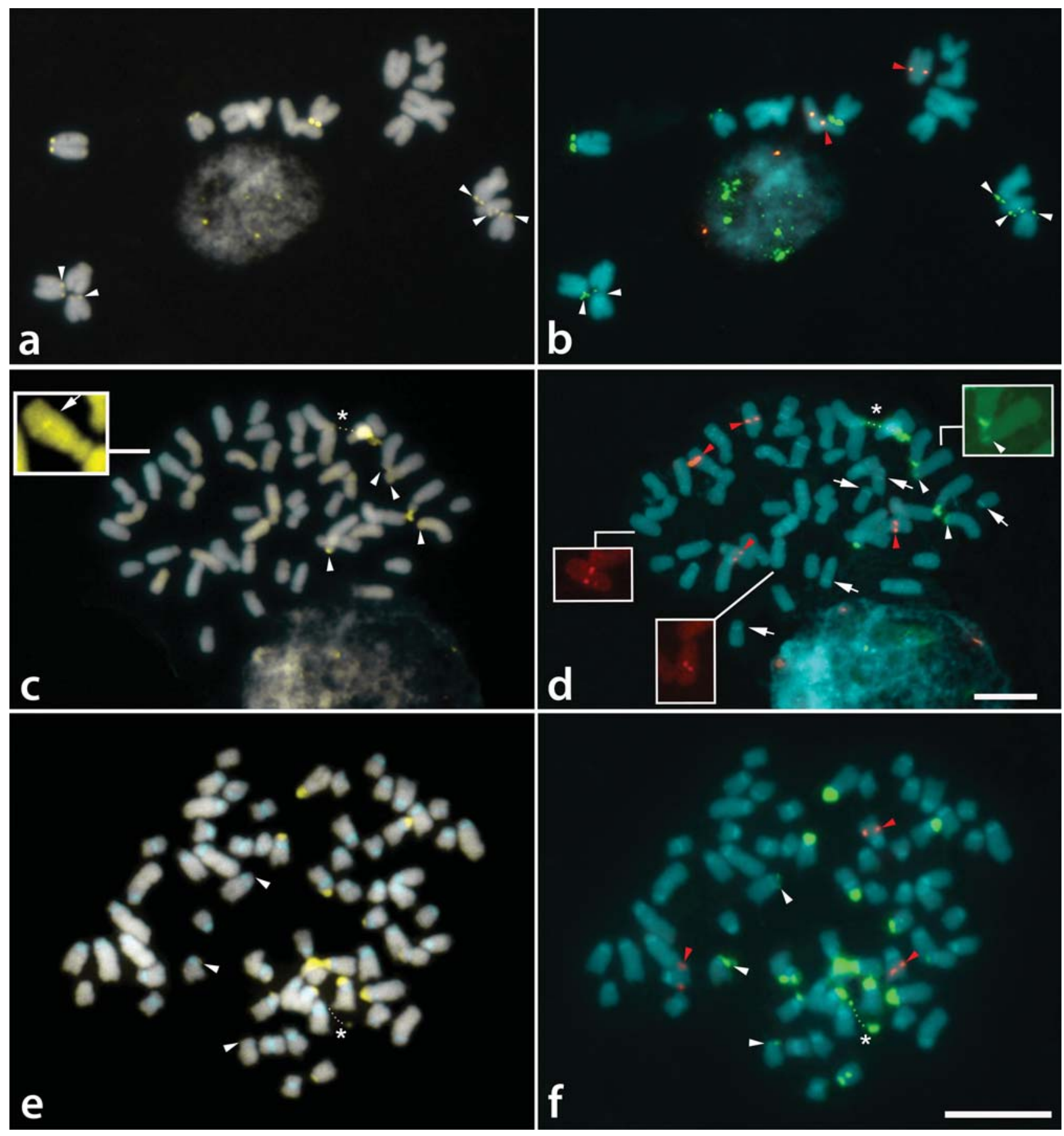

Figure 2 - Distribution of CMA/DAPI bands ( $\mathrm{a}, \mathrm{c}, \mathrm{e})$ and rDNA sites (b, d, f) in Tripogandra species. a, b - Tripogandra glandulosa; $\mathrm{c}, \mathrm{d}-T$. serrulata; $\mathrm{e}, \mathrm{f}$ - T. diuretica. White arrowheads indicate small $\mathrm{CMA}^{+}$bands and small $45 \mathrm{~S}$ rDNA sites. Red arrowheads indicate $5 \mathrm{~S}$ rDNA sites. Arrows in d point to $\mathrm{DAPI}^{+}$bands that appear only after FISH. Dots in c-f indicate secondary constrictions (asterisks). Insert in c shows CMA ${ }^{+}$band co-localized with $5 \mathrm{~S}$ rDNA; inserts in d show weak $5 \mathrm{~S}$ (red) and 45S rDNA (green) signals. Bar in d is valid for a-d and in $\mathrm{f}$ is valid for e-f. Bars correspond to $10 \mu \mathrm{m}$. 


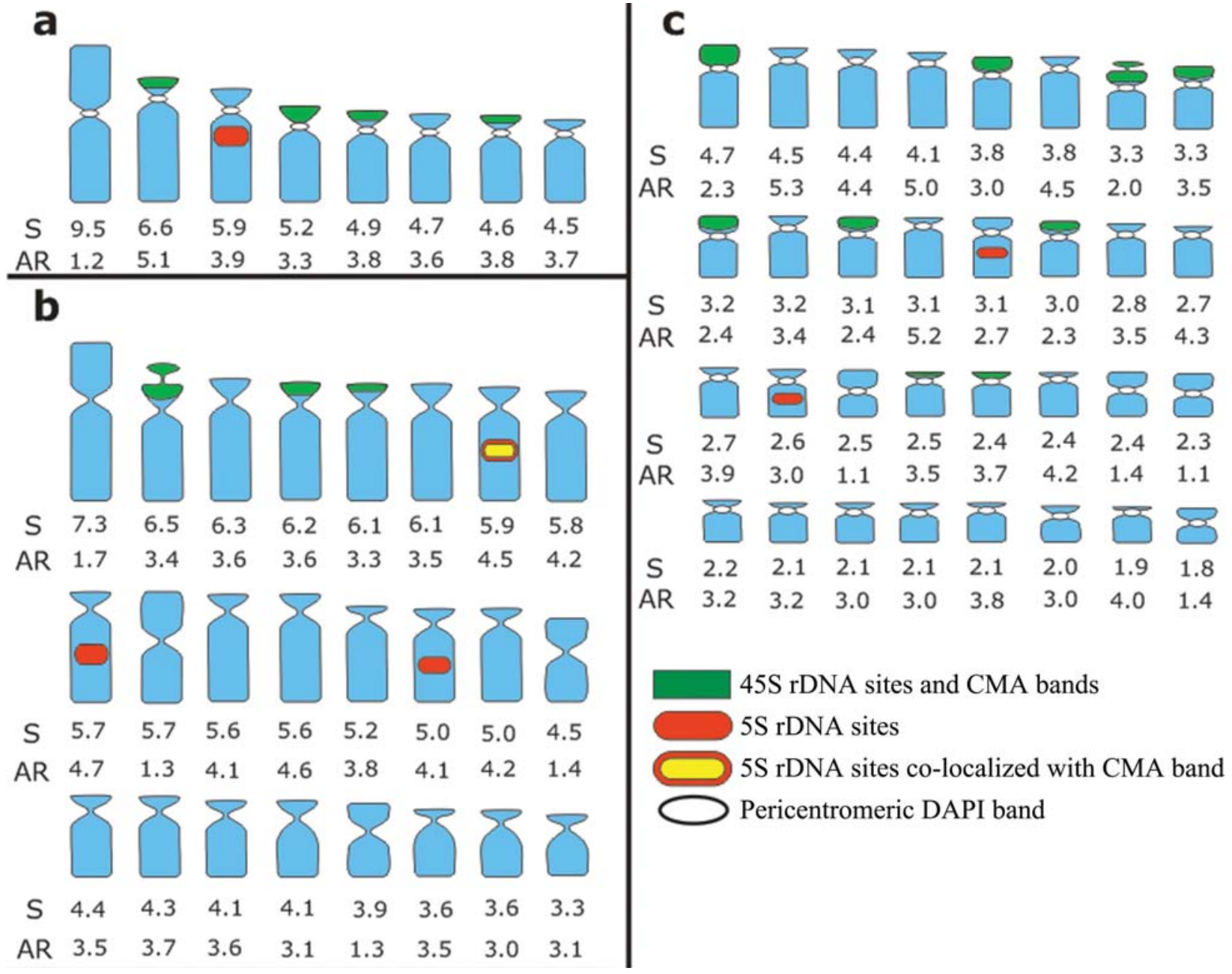

Figure 3 - Idiograms of the three species of Tripogandra analyzed, including chromosome size in $\mu \mathrm{m}$ (S), arm ratio (AR), distribution of rDNA sites, and CMA and DAPI bands. a - Tripogandra glandulosa $(2 n=16) ; \mathrm{b}-T$. serrulata $(2 n=48) ; \mathrm{c}-T$. diuretica $(2 n=64)$.

$12 \mathrm{SM}+44 \mathrm{~A})]$ showed a number of metacentric chromosomes that were proportional to those expected based on the karyotype formulae of the diploid T. glandulosa. However, the metacentric chromosomes of the hexaploid $T$. serrulata and the octoploid $T$. diuretica were much smaller than those observed in $T$. glandulosa, suggesting that they may be non-homeologous. The divergence is even more evident in the number of acrocentric chromosomes expected (56A) and observed (44A) in the octoploid. Therefore, these polyploids are probably not directly related to $T$. glandulosa.

The average haploid set length (HSL) of $T$. glandulosa complement $(45.6 \mu \mathrm{m})$ and T. serrulata $(123.8$ $\mu \mathrm{m})$ was proportional to the ploidy level and DNA amount ( $T$. glandulosa, $1 \mathrm{C}=3.2 \mathrm{pg} ;$ T serrulata, $1 \mathrm{C}=9.75 \mathrm{pg}$; Bennett and Leitch, 1995). On the other hand, the HSL of $T$. diuretica was much smaller than expected, based on the variation on ploidy level, a trend to genome downsizing more commonly found in old polyploids (Leitch and Bennett, 2004). No DNA content estimate was found for this species. The difference in the average chromosome size of $T$. serrulata and $T$. diuretica suggests that these polyploids represent different evolutionary lineages, with $T$. serrulata being younger than $T$. diuretica. Accordingly, these species differ in several morphological characters, such as the number of stamens, style/ovary relative length, type of stigma, fruit form, and surface of seed testa (Handlos, 1970, 1975). In addition, $T$. diuretica has a South American distribution from Bolivia to Argentina, whereas T. serrulata occurs from Mexico to Peru and the Caribbean.

The two polyploids also differed in their meiotic behavior. Tripogandra diuretica showed a completely regular meiosis, whereas $T$. serrulata displayed a series of meiotic irregularities, including an elevated number of univalents, anaphase bridges, and micronuclei. Curiously, Celarier (1955) reported a hexaploid specimen of $T$. serrulata with 24 bivalents and normal meiosis, suggesting the existence of different hexaploid cytotypes within this species. Thus, T. serrulata seems to be a complex species, having populations with normal meiosis as well as populations with highly irregular meiosis. 

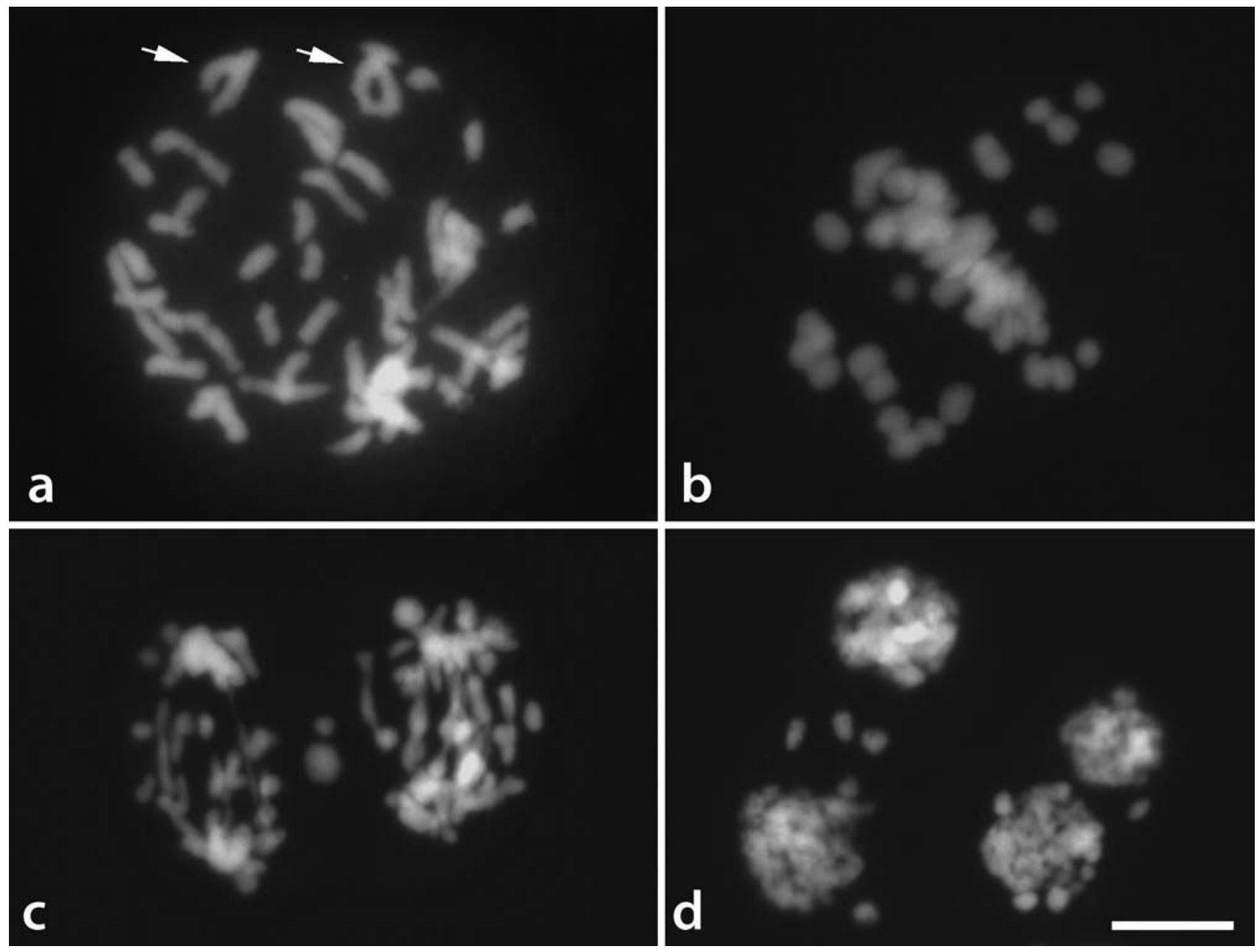

Figure 4 - Irregular meiosis in Tripogandra serrulata. a - Diakinesis, arrows point to bivalents with one or two (ring) chiasmas. $\mathrm{b}$ - Metaphase I with ca.15 bivalents and ca.18 univalents. c - Anaphase II with several bridges and laggard chromosomes; $\mathrm{d}-$ Telophase II with micronuclei. Bar corresponds to $10 \mu \mathrm{m}$.

Analyses of the interphase nuclear structure of the three species examined here revealed an additional difference in their chromatin organization, which was reticulate in the diploid, semi-reticulate with chromocenters in the octoploid, and intermediate between these types in the hexaploid. This variation depends in part on the average chromosome size, which is generally larger in species with reticulate nuclei (Guerra, 1987). Interestingly, the differences in the interphase nuclei were not reflected in the condensation pattern of their prophase chromosomes, as has been observed in other species (Delay, 1949; Guerra, 1987).

The heterochromatin in these species is of two distinct types: $\mathrm{DAPI}^{+}$, observed in the proximal regions of $T$. glandulosa and T. diuretica, and $\mathrm{CMA}^{+}$, which was terminally located in all three species. The $\mathrm{DAPI}^{+}$bands observed in $T$. serrulata only after FISH are probably not AT-rich and not similar to the DAPI ${ }^{+}$bands of the other two species (Barros-e-Silva and Guerra, 2010). The $\mathrm{CMA}^{+}$ heterochromatin was always co-localized with 45S rDNA sites, except in a chromosome of $T$. serrulata in which it was co-localized with a $5 \mathrm{~S}$ rDNA site. In general, only the 45S rDNA sites co-localize with $\mathrm{CMA}^{+}$bands (Moraes et al., 2007; Souza et al., 2009), although in some species the $\mathrm{CMA}^{+}$bands have been found co-localized with both $5 \mathrm{~S}$ and 45S rDNA sites (Cabral et al., 2006). The number of $\mathrm{CMA}^{+}$bands and $45 \mathrm{~S}$ rDNA sites varied broadly among the three species, without correlation to ploidy level, pointing once again to the instability of such chromosome landmarks (see Pedrosa-Harand et al., 2006; Kovarik et al., 2008).

The different karyotype parameters analyzed here varied among the three species, indicating that the basic number is the only cytological feature clearly shared by all three species. In general, $T$. glandulosa and $T$. serrulata were more similar to each other than to $T$. diuretica in chromosome sizes, karyotype formulae, and number of $5 \mathrm{~S}$ rDNA sites per monoploid chromosome complement. 


\section{Acknowledgments}

The authors wish to thank the Brazilian agencies Conselho Nacional de Desenvolvimento Científico e Tecnológico $(\mathrm{CNPq})$ and Fundação de Amparo à Ciência e Tecnologia de Pernambuco (FACEPE) for their financial support, and Dr. Robert Faden (Smithsonian Institution), Mauro Grabiele, and Dr. Julio Daviña (Universidad Nacional de Misiones) for their kind help in providing us with plant materials.

\section{References}

Barros-e-Silva AE and Guerra M (2010) The meaning of DAPI bands observed after C-banding and FISH procedures. Biotech Histochem 85:115-125.

Bennett MD and Leitch IJ (1995) Nuclear DNA amounts in angiosperms. Ann Bot 76:113-176.

Cabral JS, Felix LP and Guerra M (2006) Heterochromatin diversity and its co-localization with $5 \mathrm{~S}$ and $45 \mathrm{~S}$ rDNA sites in chromosomes of four Maxillaria species (Orchidaceae). Genet Mol Biol 29:659-664.

Celarier RP (1955) Cytology of the Tradescantieae. Bull Torrey Bot Club 82:30-38.

Delay C (1949) Recherches sur la structure dês noyaux quiescents chez les phanérogames. Rev Cyt Cytophysiol Vég 10:103228.

Evans TM, Sytsma KJ, Faden RB and Givnish TJ (2003) Phylogenetic relationships in the Commelinaceae: II. A cladistic analysis of $r b c L$ sequences and morphology. Syst Bot 28:270-292.

Guerra M (1987) Cytogenetics of Rutaceae IV. Structure and systematic significance of interphase nuclei. Cytologia 52:213-222.

Guerra M (2008) Chromosome numbers in plant cytotaxonomy: Concepts and implications. Cytogenet Genome Res 120:339-350.

Handlos WL (1970) Cytological investigations of some Commelinaceae from Mexico. Baileya 17:6-33.

Handlos WL (1975) The taxonomy of Tripogandra (Commelinaceae). Rhodora 77:218-319.

Jones K and Jopling C (1972) Chromosomes and the classification of the Commelinaceae. Bot J Linn Soc 65:129-162.

Jones K and Kenton A (1984) Mechanisms of chromosome change in the evolution of the tribe Tradescantieae (Commelinaceae). In: Sharma A and Sharma AK (eds) Chromosomes in Evolution of Eukaryotic Groups II. CRC Press, Boca Raton, pp 143-168.

Kenton A (1991) Heterochromatin accumulation, disposition and diversity in Gibasis karwinskyana (Commelinaceae). Chromosoma 100:467-478.

Kovarik A, Dadejova M, Lim YK, Chase MW, Clarkson JJ, Knapp S and Leitch AR (2008) Evolution of rDNA in Nicotiana allopolyploids: A potential link between rDNA homogenization and epigenetics. Ann Bot 101:815-823.

Leitch IJ and Bennett MD (2004) Genome downsizing in polyploid plants. Biol J Linn Soc 82:651-663.
Lewis WH, Suda Y and Oliver RL (1967) Chromosome numbers of phanerogams 2. Ann Missouri Bot Gard 54:178-180.

Moraes AP, Soares Filho WS and Guerra M (2007) Karyotype diversity and the origin of grapefruit. Chromosome Res 15:115-121.

Parokonny AS, Kenton AY, Meredith L, Owens SJ and Bennett MD (1992) Genomic divergence of allopatric sibling species studied by molecular cytogenetics of their $\mathrm{F}_{1}$ hybrids. Plant $\mathrm{J}$ 2:695-704.

Pedrosa A, Sandal N, Stougaard J, Schweizer D and Bachmair A (2002) Chromosomal map of the model legume Lotus japonicus. Genetics 161:1661-1672.

Pedrosa-Harand A, Almeida CCS, Mosiolek M, Blair MW Schweizer D and Guerra M (2006) Extensive ribosomal DNA amplication during Andean common bean (Phaseolus vulgaris L.) evolution. Theor Appl Genet 112:924-933.

Pitrez SR, Felix LP, Barreto R and Guerra M (2001) Números cromossômicos de espécies de Commelinaceae R. Br. ocorrentes no nordeste do Brasil. Bol Bot Univ São Paulo 19:714 (Abstract in English).

Sakurai T and Ichikawa S (2001) Karyotypes and Giemsa C-banding patterns of Zebrina pendula, Z. purpusii and Setcreasea purpurea, compared with those of Tradescantia ohiensis. Genes Genet Syst 76:235-242.

Simmonds NW (1954) Chromosome behaviour in some tropical plants. Heredity 8:139-146.

Souza LGR, Crosa O, Winge H and Guerra M (2009) The karyotype of Nothoscordum arenarium Herter (Gilliesioideae, Alliaceae): A populational and cytomolecular analysis. Genet Mol Biol 32:111-116.

Wanzenböck EM, Schöfer C, Schweizer D and Bachmair A (1997) Ribosomal transcription units integrated via T-DNA transformation associate with the nucleolus and do not require upstream repeat sequences for activity in Arabidopsis thaliana. Plant J 11:1007-1016.

\section{Internet Resources}

Bergamo S (2003) A phylogenetic evaluation of Callisia Loefl. (Commelinaceae) based on molecular data. PhD Thesis, The University of Georgia, USA. https://getd.libs.uga.edu/pdfs/bergamo_stephanie 200312_phd/bergamo_stephanie_200312_phd.pdf (February 26,2010$)$.

Burns JH (2006) A comparison of invasive and noninvasive Commelinaceae in a phylogenetic context. PhD Thesis. The Florida State University College of Arts and Sciences, USA. http://etd.lib.fsu.edu/theses/available/ etd-11092006-112630/unrestricted/BurnsMoriuchi_Dissertation.pdf (February 26, 2010).

Editor: Angela M. Vianna-Morgante

License information: This is an open-access article distributed under the terms of the Creative Commons Attribution License, which permits unrestricted use, distribution, and reproduction in any medium, provided the original work is properly cited. 